\title{
THE RELATIONSHIP BETWEEN DIGIT RATIO (2D:4D) AND CARDIOVASCULAR CAPACITY IN YOUNG ADULTS
}

\author{
Fatih Erkan Akay ${ }^{1}$, Betül Duran ${ }^{1}$, Mehmet Can Keyfoğlü, Selçuk Yavuz²
}

${ }^{1}$ Trakya University Faculty of Medicine, Edirne, TURKEY

${ }^{2}$ Department of Physical Medicine and Rehabilitation, Trakya University Faculty of Medicine, Edirne, TURKEY

\section{ABSTRACT}

Aims: The ratio of the second-to-fourth finger length was first proposed as a prenatal testosterone biomarker. Studying this matter with a different point of view, the aim of this study is to find whether there is a positive relationship between digit ratio and cardiovascular capacity.

Methods: The data of 82 students who were between the ages of 18 and 25 old from Trakya University Faculty of Medicine were analyzed by evaluating the results of the six-minute walking test and the results of their digit measurements. Independent Samples T-Test was used to determine the correlation between the prevalence of longer 4th digit and six-minute walking test results.

Results: The data obtained from the test results of the students, that were grouped regarding digit ratio, were statistically evaluated. With the results of the six-minute walking test, students that have lower digit ratio walked $593.87 \pm$ 73.2 meters while students with higher digit ratio walked $584.17 \pm 71$ meters showing us that there is not a significant relationship between cardiovascular capacity and digit ratio.

Conclusion: With the gathered information and results, it is seen that there is not a positive relationship between digit ratio and cardiovascular capacity. In conclusion it can be said that digit ratio does not have a beneficial effect on a persons cardiovascular capacity. Usage of digit ratio as a prenatal hormone exposure has been increasing, and extensive studies in physiological and psychological conditions in humans have been correlated with digit ratio, including athletic ability, fertility, social behaviors, sex-biased diseases, and sexual orientation.

Keywords: Fingers, androgenization, testosterone,

\section{INTRODUCTION}

Recent studies show that prenatal testosterone exposure during the second trimester of gestation can be reflected in a person's digit ratio (2D:4D) (1). If the digit ratio is low, prenatal testosterone exposure is expected to be higher, making the 4 th digit finger longer than 2nd. Human perinatal testosterone production consists of three distinct peaks, a mid-gestational peak, and two postnatal peaks. In these three distinct peaks, the mid- gestational peak is known to have an important biological effect on producing the differences between sex at birth. However, the sex differentiation may continue after birth (1).
Since peripheral blood cannot be drawn from a fetus in utero, researchers interested in studying the effects of perinatal testosterone had to rely on a variety of other methods (1). The use of finger or digit length ratio measurement of 2D:4D was proposed as a prenatal testosterone marker by John Manning et al (2) in 1998.

As mentioned before the lack of peripheral blood measurement from fetuses in utero is an important obstacle to the direct validation of $2 \mathrm{D}: 4 \mathrm{D}$ or any adult marker for perinatal androgen action (1). However, there are other alternative methods for direct fetal androgen measurement that have been a useful research tool validating $2 \mathrm{D}: 4 \mathrm{D}$ ratios such as amniotic fluid, neonatal cord blood, and gravid maternal blood. 
In this study, our aim is to research whether there is positive relationship between digit ratio and cardiovascular capacity. To define cardiovascular capacity, six-minute walking test is used and linked with digit ratio, therefore it is expected that people with lower digit ratio have higher cardiovascular capacity which causes them to walk longer in given time.

\section{MATERIAL AND METHODS}

This study was approved by Scientific Researches Ethics Committee of Trakya University Medical Faculty. The study included 82 students from Trakya University Medical Faculty with the age range of 18 to 25, and carried out in Trakya University Physical Therapy and Rehabilitation Center from 19 to 29 June 2017. The study has an observational, descriptive and cross-sectional design. The sample size of 82 students was determined by performing power analysis.

The subjects are divided in 2 groups, as the ones with the digit ratio lower than 1 included to "lower digit ratio group", higher than 1 to "higher digit ratio group". 4th and 2nd digits length were measured from the most proximal crease to the finger tip using a caliper. To eliminate bias due to observational errors, all digits were measured by one researcher.

Considering the result of the power analysis, it was determined to have at least 41 participants in each group, thus first 41 participants with higher and 41 with lower digit ratio were selected for 6MWT after measuring their digits. Before and after 6MWT students heart rates were measured with a pulse oximeter. $6 \mathrm{MWT}$ provides information by measuring the distance $(\mathrm{m})$ an individual is able to walk over a total of six minutes on a 60 meter long hard, flat surface, thus gives us information about a person's cardiovascular capacity. The obtained data were recorded and statistical analysis was performed.

Student $t$ test was performed to compare both groups in regard to their pulse rates before and after $6 \mathrm{MWT}$, also the average covered distance. As for descriptive statistics, mean \pm standard deviation and numbers were used. $\mathrm{P}$ value $<0.05$ is considered statistically significant.

\section{RESULTS}

In the present study, the population was composed of 82 students. Out of the total 82 students who were included in the study, 41 were with higher digit ratio and 41 were with lower digit ratio. Baseline demographics and physical characteristics of study subjects are demonstrated in Table 1.

Table 1: Baseline demographic and physical characteristics of the study subjects

\begin{tabular}{|l|l|l|l|}
\hline & $\begin{array}{l}\text { Higher Digit } \\
\text { Ratio }(\mathbf{n}=\mathbf{4 1})\end{array}$ & $\begin{array}{l}\text { Lower Digit } \\
\text { Ratio }(\mathbf{n}=\mathbf{4 1})\end{array}$ & P value \\
\hline Height & $1.68 \pm 0.07$ & $1.71 \pm 0.08$ & 0.045 \\
\hline Weight & $61.08 \pm 11.5$ & $65.69 \pm 11.6$ & 0.077 \\
\hline BMI & $21.05 \pm 3.02$ & $21.62 \pm 2.46$ & 0.356 \\
\hline
\end{tabular}

Data are represented as mean values \pm Standart Deviation (SD), BMI= Body Mass Index.

The average digit ratios are calculated as: 0.956 for lower digit ratio group, 1,027 for higher digit ratio group. The average the pulse values before and after walking, also the average distance of subjects are shown in Table 2. As the result of the performed statistical analysis, no statistically significant different between 2 groups were detected.

Table 2: Results of six-minute walking test (6MWT)

\begin{tabular}{|l|l|l|l|}
\hline & $\begin{array}{l}\text { Higher Digit } \\
\text { Ratio }(\mathbf{n}=\mathbf{4 1})\end{array}$ & $\begin{array}{l}\text { Lower Digit } \\
\text { Ratio }(\mathbf{n}=\mathbf{4 1})\end{array}$ & P value \\
\hline Pulse (before) & $82.72 \pm 12.9$ & $82.29 \pm 11.4$ & 0.874 \\
\hline Walked (meter) & $593.87 \pm 73.2$ & $584.17 \pm 71$ & 0.547 \\
\hline Pulse (after) & $114.21 \pm 26.7$ & $113.00 \pm 18.6$ & 0.813 \\
\hline
\end{tabular}

\section{DISCUSSION}

Our aim in this study was to elucidate the effect of digit ratio (DR) on a person's cardiovascular capacity. It was expected that students with lower digit ratio would walk longer in $6 \mathrm{MWT}$ which shows the person's cardiovascular capacity. The results did not show us a statistically significant difference between students with higher and lower DR hence, however students with higher DR walked longer than students with lower DR despite having higher BMI and lower pulse after 6MWT. 
It was found that in mice 4th digit has higher androgen receptor and estrogen receptor $\alpha$ (ER- $\alpha)$ activity than 2 nd digit (3). If the androgen receptor activity is lower, 4 th digit tends to grow less which causes a higher DR (3). Whereas, inactivation of ER- $\alpha$ causes a higher growth on 4th digit (3). However, development mechanism of digit ratio still remains unknown in humans. In 1998 digit ratio was concerned as a prenatal testosterone biomarker, a study showed us that men with lower 2D:4D ratio had lower estrogen and higher serum testosterone, which lead to a hypothesis that people with lower 2D:4D had a higher prenatal testosterone exposure than people with higher 2D:4D making their 4 th digit longer (2).

In our study, DR was correlated with cardiovascular capacity and was expected to be seen whether people with lower DR have the higher cardiovascular capacity. Similar researches were not found like ours, however, with the gathered information it was seen that DR corresponded with sports performances (4). In the study of M. Bennet et al. (5) found that rugby players with lower DR had better performances. Also Frcik NA et al. (6) found out that basketball players that have lower left 2D:4D achieved higher competitive standards. In other researches it was seen that professional football players had lower 2D:4D ratios and compared to males with higher DR, men with lower DR acquired higher attainment in variety of sports and had higher mental rotation scores(a measure of visual-spatial ability) (7). The only research that can be associated with was done by Longman $\mathrm{D}$ et al. (8) comparison of digit ratio with rowing that needs a more developed cardiovascular system and higher power output. Unlike our results, they found significant negative correlations between male digit ratios and 2,000 m ergometer performance. This shows that prenatal testosterone exposure can have a long-term effect on a person's traits associated with physical power in males.

As previously stated DR is used for other purposes as well. For example, it is seen than heterosexual women are exposed to less prenatal androgen exposure than homosexual women, also men that are exposed to more prenatal androgen than their older brother are more likely to be homosexual in their adulthood (9). DR can have an effect on social behavior (10) and fertility (11) as well. On the other hand, digit ratio is also used as an indicator for some sex-biased disease $(12,13)$, such as; infertility, autism, dyslexia, migraine, stammering, immune dysfunction, myocardial infarction and breast cancer. Additionally, DR can be a base to further expand the knowledge in numerous scientific researches.

Even though expected amount of people were reached, limitation factor was that 6MWT may not be enough to determine a person's cardiovascular capacity, for better results more options can be used. For instance, increasing the number of measured students and with the 6MWT, usage of exercise electrocardiogram may give more reliable results. Furthermore, expanding the measurement system may lead us to accomplish better results.

Ethics Committee Approval: This study was approved by Scientific Researches Ethics Committee of Trakya University Medical Faculty.

Informed Consent: Verbal informed consent was obtained from the participants of this study.

Conflict of Interest: The authors declared no conflict of interest.

Financial Disclosure: The authors declared that this study received no financial support.

\section{REFERENCES}

1. Matthew $H$. The use of digit ratios as markers for perinatal androgen action. Reprod Biol Endocrinol 2006;4:10.

2. Manning JT, Scutt D, Wilson J et al. The ratio of 2nd to 4th digit length: a predictor of sperm numbers and concentrations of testosterone, luteinizing hormone and estrogen. Human Reprod. 1998;13(11):3000-4.

3. Zhengui Z, Martin JC. Developmental basis of sexually dimorphic digit ratios. Proc Natl Acad Sci U S A. 2011 Sep 27;108(39):16289 - 94.

4. Tae Beom K, Khae Hawn K. Why is digit ratio correlated to sports performance? Journal of Exercise Rehabilitation J Exerc Rehabil 2016 Dec; 12(6): 515 - 9.

5. Bennett M, Manning JT, Cook CJ et al. Digit ratio (2D:4D) and performance in elite rugby players. J Sports Sci 2010;28:1415 - 21.

6. Frick NA, Hull MJ, Manning JT et al. Relationships between digit ratio (2D:4D) and basketball performance in Australian men. Am J Hum Biol 2017;29(3) 
7. Manning JT, Taylor RP. Second to fourth digit ratio and male ability in sport: implications for sexual selection in humans. Evol Hum Behav. 2001 Jan;22(1): 6169.

8. Longmont D, Stock JT, Wells JC. Digit ratio (2D:4D) and rowing ergometer performance in males and females. Am J Phys Anthropol 2011;144(3): 337 - 41.

9. Terrance JW, Michelle EP, Scott EC et al. Finger-length ratios and sexual orientation. Nature 404, 2000 March 30: 455 - 56.

10. John MC, Mark G, Aldo R. Second-to-fourth digit ratio predicts success among high-frequency financial traders. Proc Natl Acad Sci USA 106:623 - 28

11. Manning JT, Barley L, Walton J et al. The 2nd:4th digit ratio, sexual dimorphism, population differences, and reproductive success. evidence for sexually antagonistic genes? Evol Hum Behav. 2000 May 1;21(3):163 - 83.

12. Manning JT, Baron-Cohen S, Wheelwright $S$ et al. The 2nd to 4th digit ratio and autism. Dev Med Child Neurol. 2001 Mar;43(3): 160 - 4.

13. Manning JT, Bundred PE. The ratio of 2 nd to 4 th digit length: a new predictor of disease predisposition? Med Hypotheses. 2000 May;54(5): 855 - 7. 